\title{
Literasi Numerasi Dalam Pembelajaran Tematik Siswa Kelas Atas Sekolah Dasar
}

\author{
Ryzal Perdana ${ }^{a}, 1^{\star}$, Meidawati Suswandari $\mathrm{b}, 2$ \\ a Pascasarjana Ilmu Pendidikan, Universitas Lampung, Lampung, Indonesia \\ ${ }^{\mathrm{b}}$ Fakultas Keguruan dan Ilmu Pendidikan, Universitas Veteran Bangun Nusantara, Sukoharjo, Indonesia \\ 1 ryzalperdana2009@gmail.com*; ${ }^{2}$ moetis_meida@yahoo.co.id \\ * Corresponding Author
}

Diterima 19 Maret 2021; Disetujui 20 Maret 2021; Diterbitkan 20 Maret 2021

\begin{abstract}
The purpose of this study was to describe numeracy literacy in the thematic learning of senior elementary school students. This writing is done through literature study. The object of this research is numeracy literacy and thematic learning. The research subjects were elementary school upper class students. The data collection tool in this research is to search journals contained in several electronic media such as digital libraries, the internet, through Google Scholar. The data analysis technique used in this study was annotated bibliography analysis. The results showed that numeracy literacy in thematic learning of upper grade students of elementary school can be done by providing stimulus to students. To stimulate student curiosity, the availability of facilities and infrastructure, the capacity of school residents, and the capacity of stakeholders, a numeracy literacy work program twice a week before learning hours takes place, a mathematics and non-mathematics teacher training for thematic learning based on numeracy literacy is held, and fostering love reading to students and learning experiences that are fun while stimulating the imagination.
\end{abstract}

\section{KEYWORDS}

Numeracy Literacy Thematic Learning Upper Class Elementary School Keyword_5

This is an openaccess article under the CC-BY-SA license

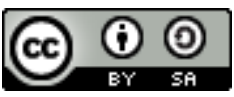

\section{Pendahuluan}

Budaya literasi di Indonesia menjadi persoalan yang sangat menarik untuk diperbincangkan. Mengingat budaya literasi di Indonesia masih rendah, belum membudaya, dan belum mendarah daging dikalangan masyarakat. Ditengah melesatnya budaya populer, buku tidak pernah lagi menjadi prioritas utama. Bahkan masyarakat lebih mudah menyerap budaya berbicara dan mendengar, dari pada membaca kemudian menuangkannya dalam bentuk tulisan. Masyarakat Indonesia masih lebih banyak didominasi oleh budaya komunikasi lisan atau budaya tutur. Masyarakat cenderung lebih senang menonton HP dengan update status dan mengikuti siaran televisi daripada membaca (Suswandari, 2018).

Berdasarkan survey PISA adalah Programme for International Students Assessment untuk beberapa siswa usia 15 tahun. Peringkat literasi matematis siswa Indonesia sejak tahun 2009 hingga 2015 tidak menunjukan adanya kenaikan yang signifikan. Tahun 2009 Indonesia berada pada peringkat 68 dari 74 negera. Tahun 2012 Indonesia di urutan 64 dari 65 negara dengan tingkat pencapaian relatif rendah. Sedangkan hasil PISA di tahun 2015 menunjukan peringkat Indonesia mengalami sedikit kenaikan urutan yaitu 63 dari 72 negara. Hasil selama tiga kali survey menunjukan kemampuan peserta didik di Indonesia pada literasi matematis khususnya masih tergolong sangat rendah dibandingkan dengan negara peserta PISA lainnya (Ayuningtyas \& Sukriyah, 2020).

Di Indonesia melalui program pemerintah Kementerian Pendidikan dan Kebudayaan tahun 2016 mewacanakan Gerakan Literasi Nasional (GLN). Gerakan Literasi Nasional merupakan implementasi dari Permendikbud Nomor 23 Tahun 2015 tentang Penumbuhan Budi Pekerti. Gerakan Literasi Nasional (GLN) yang telah dicanangkan pemerintah, dilaksanakan pendidikan melalui sekolah yang disebut dengan Gerakan Literasi Sekolah (GLS). Gerakan Literasi Sekolah dapat diartikan sebagai upaya yang dilakukan untuk mewujudkan organisasi pebelajar yang literat dan menumbuhkan budi pekerti bagi warga sekolah melalui berbagai aktivitas meliputi kegiatan membaca buku non pembelajaran selama 15 menit (Ekowati et al., 2019; Suswandari, 2018). 
Salah satu Gerakan Literasi Sekolah adalah dalam bentuk literasi numerasi. Literasi numerasi adalah pengetahuan dan kecakapan untuk menggunakan berbagai macam angka dan simbol terkait dengan matematika dasar untuk memecahkan masalah praktis dalam kehidupan sehari-hari lalu menganalisis informasi yang ditampilkan dalam berbagai bentuk serta menginterpretasi hasil analisis untuk memprediksi dan mengambil keputusan (Kemdikbud dalam Mahmud \& Pratiwi, 2019).

Sedangkan dalam pandangan Ekowati et al., (2019) literasi numerasi diartikan sebagai kemampuan seseorang dalam menggunakan penalaran. Penalaran berarti menganalisis dan memahami suatu pernyataan, melalui aktivitas dalam memanipulasi symbol atau bahasa matematika yang ditemukan dalam kehidupan sehari-hari, dan mengungkapkan pernyataan tersebut melalui tulisan maupun lisan.

Literasi numerasi terdiri dari tiga aspek berupa berhitung, relasi numerasi, dan operasi aritmatik. Berhitung adalah kemampuan untuk menghitung suatu benda secara verbal dan kemampuan untuk mengidentifikasi jumlah dari benda. Relasi numerasi berkaitan dengan kemampuan untuk membedakan kuantitas suatu benda seperti lebih banyak, lebih sedikit, lebih tinggi, atau lebih pendek. Sementara itu, operasi aritmatika adalah kemampuan untuk mengerjakan operasi matematika dasar berupa penjumlahan dan pengurangan. Tiga aspek literasi numerasi yang telah dijelaskan sebelumnya merupakan aspek dasar dalam pembelajaran matematika yang penting diperkenalkan sejak usia dini hingga anak memasuki kelas rendah (Mahmud \& Pratiwi, 2019).

Matematika merupakan salah satu bidang studi yang diajarkan di lembaga pendidikan formal yang merupakan salah satu bagian penting dalam upaya meningkatkan mutu pendidikan. Pelajaran matematika adalah suatu pelajaran yang berhubungan dengan banyak konsep. Konsep merupakan ide abstrak yang dengannya kita dapat mengelompokkan obyek-obyek kedalam contoh atau bukan contoh. Konsep-konsep dalam matematika memiliki keterkaitan satu dengan yang lainnya. Saling keterkaitannya antar konsep materi satu dan yang lainnya merupakan bukti akan pentingnya pemahaman konsep matematika (Novitasari, 2016).

Faktanya salah satu penyebab kegagalan dalam pembelajaran matematika adalah siswa tidak paham konsep-konsep matematika atau siswa salah dalam memahami konsep-konsep matematika. Kesalahan konsep suatu pengetahuan saat disampaikan di salah satu jenjang pendidikan, bisa berakibat kesalahan pengertian dasar hingga ke tingkat pendidikan yang lebih tinggi. Hal ini terjadi karena matematika adalah materi pembelajaran yang saling berkaitan satu sama lain (Novitasari, 2016).

Pentingnya kemampuan literasi numerasi dapat dicermati melalui contoh berikut, seorang siswa belajar konsep perkalian bilangan bulat dengan bilangan bulat. Dua kali tiga adalah enam. Hasil tersebut tetap sama walaupun soal diganti dengan tiga kali dua. Namun, akan berbeda ketika diberikan dalam situasi pemberian obat. Aturan pemberian obat dua kali tiga dengan tiga kali dua akan memberikan efek penyerapan dan penyembuhan yang berbeda. Dengan penguasaan konsep perkalian bilangan bulat dan kemampuan numerasi yang baik siswa akan mampu menjelaskan alasan mengapa efek penyerapan obat itu berbeda. Contoh lain dalam situasi yang berbeda, bus yang akan digunakan pada kegiatan studi wisata berkapasitas 48 orang. Jika peserta studi wisata ternyata 165 orang maka bagaimana cara untuk mengefisienkan biaya bus?. Pada soal ini siswa belajar menyadari bahwa meskipun hasil dari 165:48 adalah 3,44 tetapi dalam kegiatan wisata tersebut setidaknya memerlukan empat bus pariwisata. Konsep pembulatan bilangan tidak digunakan dalam soal ini. Selanjutnya, agar biaya menjadi efisien kapasitas bus keempat dipilih sesuai dengan kekurangan kursi peserta bukan menggunakan empat bus berkapasitas 48 orang (Tyas \& Pangesti, 2018).

Sementara itu, kebijakan Kemendikbud melalui kurikulum 2013 mencanangkan adanya pembelajaran tematik khususnya dalam muatan pelajaran matematika. Pembelajaran tematik merupakan pendekatan pembelajaran yang mengintegrasikan berbagai kompetensi dari berbagai mata pelajaran ke dalam berbagai tema. Pengintegrasian terwujud dalam dua hal, yakni: (1) integrasi sikap, keterampilan, dan pengetahuan dalam proses pembelajaran; dan (2) integrasi berbagai konsep dasar yang terkait. Tema dikemas dalam berbagai konsep sehingga siswa tidak belajar konsep pengetahuan/pemahaman secara terpisah. Oleh sebab itu, pembelajaran dapat bermakna dan berjalan utuh (Rusman, 2011: 255). 
Pembelajaran tematik dibutuhkan guru yang kreatif untuk merangkai pembelajaran yang padu. Mencari kaitan antar mata pelajaran sehingga siswa tidak akan merasakan bahwa mata pelajaran sudah berganti. Upaya guru untuk mengatasi kesulitan dalam mengkaitkan tema dengan cara: menggambarkan terlebih dahulu jaringan tema, sehingga akan mudah dalam mencari kaitannya. Dengan menggambarkan jaringan tema serta indikatornya akan memudahkan guru dalam menemukan kaitan dari beberapa mata pelajaran tersebut; membuat skenario pembelajaran yang disesuaikan dengan jaringan tema dan kaitan antar mata pelajaran yang telah ditemukan untuk menciptakan pembelajaran yang menyenangkan (Wahyuni, Setyosari, \& Kuswandi, 2016: 134-135). Oleh sebab itu, penting untuk memahami lebih jauh tentang literasi numerik dalam pembelajaran tematik pada muatan pelajaran matematik siswa kelas atas Sekolah Dasar.

\section{Metode}

Penulisan ini dilakukan melalui studi pustaka. Kegiatan dilakukan secara sistematis untuk mengumpulkan, mengolah, dan menyimpulkan data dengan menggunakan metode/teknik tertentu guna mencari jawaban atas permasalahan yang dihadapi (Dits Prasanti, 2018). Penelitian studi pustaka adalah kegiatan penelitian dilakukan dengan cara mengumpulkan informasi dan data dengan bantuan berbagai macam material yang ada di perpustakaan seperti buku referensi, hasil penelitian sebelumnya yang sejenis, artikel, catatan, serta berbagai jurnal yang berkaitan dengan masalah yang ingin dipecahkan. Studi pustaka dalam penelitian ini yang dilakukan dengan mengkaji mengenai konsep dan teori yang digunakan berdasarkan literatur yang tersedia, yang diantaranya artikel-artikel yang dipublikasikan dalam jurnal ilmiah yang berisi teori-teori yang relevan dengan masalahmasalah penelitian. Obyek penelitian ini adalah literasi numerasi, pembelajaran tematik, dan muatan pelajaran matematika. Subyek penelitian ini yaitu siswa kelas atas sekolah dasar.

Alat pengumpulan data dalam penelitian ini adalah dengan melakukan penelusuran jurnal-jurnal yang terdapat pada beberapa media elektronik seperti digital library, internet, dengan melalui Google Scholar. Google Scholar juga bisa disebut Google Cendekia dalam bahasa indonesia. Google Scholar ini menyediakan layanan seperti informasi yang pastinya bermanfaat berupa PDF (Portable Document Format) secara lengkap dan gratis. Pada umumnya Google Scholar digunakan oleh kalangan pelajar dan mahasiswa untuk mencari referensi dalam membuat karya ilmiah (Rafika et al., 2017).

Kata kunci yang digunakan dalam penelusuran pada jurnal dan buku yang relevan dalam penelitian studi pustaka ini adalah "literasi numerasi", "matematika", dan "pembelajaran matematika". Oleh sebab itu, alat pengumpulan data dalam artikel ini dengan menggunakan jurnaljurnal yang terdapat pada Google Cendekia atau Google Scholar.

Teknik analisis data yang digunakan dalam penelitian ini adalah analisis anotasi bibliografi (annotated bibliography) yang artinya suatu kesimpulan sederhana dari suatu artikel, buku, jurnal, atau beberapa sumber tulisan lain. Dengan adanya bibliografi dapat membantu menjaga kelestarian koleksi, karena melalui bibliografi pemustaka tidak menemukan dokumen perpustakaan secara langsung melainkan hanya memperoleh informasi tentang adanya suatu dokumen pustaka yang memuat suatu informasi yang dicari, sehingga koleksi perpustakaan dapat dilestarikan dengan baik (Yanto, S \& Nelisa, 2014). Bibliografi diartikan sebagai suatu daftar sumber dari suatu topik. Selain itu dapat didefinisikan bibliografi yang setiap koleksi yang dimuat diberi keterangan mengenai isi buku atau informasi lain yang memudahkan pembaca mengetahui pembahasan yang dibahas didalam buku tersebut. Anotasi bibliografi penelitian ini berasal dari buku dan jurnal relevan melalui penelusuran artikel ilmih hasil penelitian yang sebelumnya.

\section{Hasil dan Pembahasan}

Sekolah Dasar merupakan proses belajar kelanjutan dari kelompok bermain, PAUD, dan taman kanak-kanak. Di lingkungan sekolah dikenalkan proses belajar yang tidak hanya tentang kehidupan nyata tapi juga teori dan proses dididik menjadi lebih baik untuk perubahan ide dan tingkah laku. Khususnya di Sekolah Dasar terbagi atas kelas rendah dan kelas tinggi. Kelas rendah meliputi siswa kelas I, II, dan III. Sedangkan kelas tinggi meliputi kelas IV, V, dan VI.

Proses tumbuh dan kembang anak di sekolah akan mulai menapaki berpikir kritis lebih kreatif dan inovati manakala di kelas tinggi. Nasution mengatakan bahwa masa kelas atas/tinggi sekolah 
dasar mempunyai beberapa sifat khas sebagai berikut : (1) adanya minat terhadap kehidupan praktis sehari-hari yang kongkrit. (2) amat realistik, ingin tahu dan ingin belajar. (3) menjelang akhir masa ini telah ada minat terhadap hal-hal dan mata pelajaran khusus, oleh ahli yang mengikuti teori faktor ditaksirkan sebagai mulai menonjolnya faktor-faktor. (4) pada umumnya anak menghadap tugastugasnya dengan bebas dan berusaha menyelesaikan sendiri. (5) pada masa ini anak memandang nilai (angka rapor) sebagai ukuran yang tepat mengenai prestasi sekolah. (6) anak pada masa ini gemar membentuk kelompok sebaya, biasanya untuk bermain bersama-sama. Berdasarkan karakteristik siswa yang telah diuraikan seperti di atas, guru diharapkan sudah mengemas pembelajaran dalam bentuk perencanaan dan pengalaman belajar yang akan diberikan kepada siswa dengan baik, menyampaikan hal-hal yang ada di lingkungan sekitar kehidupan siswa sehari-hari, sehingga materi pelajaran yang dipelajari tidak abstrak dan lebih bermakna bagi anak (Dayang et al., 2013; Kawaryan, 2018; Ramandanu, 2019; Septianti \& Afiani, 2020).

Karakteristik siswa kelas atas perlu juga seorang guru sudah mengarahkan pada pembelajaran yang tidak hanya monoton tapi juga memberi stimulus pada siswa. Stimulus yang dipilih hendaknya kontekstual, menarik, dan sebaiknya bersifat kekinian sehingga merangsang rasa ingin tahu siswa (Tyas \& Pangesti, 2018). Stimulus pada siswa terutama dalam hal literasi numerasi.

Permasalahan utama yang menyebabkan siswa masih belum dapat menyelesaikan pembelajaran yang berbasis literasi numerasi adalah guru yang belum membiasakan siswa dengan soal-soal berbasis literasi. Hal ini disebabkan masih banyak guru yang masih belum mampu menyusun soal literasi numerasi terutama untuk guru-guru di tingkat sekolah dasar agar siswa menjadi lebih terbiasa untuk menyelesaiakn soal-soal non-rutin tersebut. Guru cenderung membuat soal rutin yang tertutup dan dapat langsung diselesaikan dengan penggunaan suatu rumus (Kartikasari, Kusmayadi, \& Usodo dalam Fiangga et al., 2019).

Lange menyatakan bahwa literasi numersi dalam matematika ditandai oleh beberapa kompetensi utama, yaitu: (1). Berpikir dan bernalar matematika, yaitu meliputi kemampuan mengajukan pertanyaan berciri matematika; mengetahui sejumlah jawaban yang bisa ditawarkan oleh matematika; memahami keluasan maupun keterbatasan konsep matematika serta mampu menyiasatinya. (2). Berargumen matematika, yaitu mengetahui apa yang dimaksud dengan bukti; mengetahui perbedaan antara bukti dan penalaran matematika lainnya; mampu mengikuti dan menilai urutan dalam gagasan; mampu membuat dan mengetahui gagasan matematika. (3). Komunikasi matematika, yaitu mampu menyatakan gagasan dalam berbagai bentuk baik lisan, tulisan dan bentuk visual lainnya; memahami hasil pekerjaan orang lain. (4). Pemodelan, yaitu kemampuan menerjemahkan realitas ke dalam bentuk matematika; sebaiknya, menafsirkan model matematika dalam konteks atau realitasnya; bekerja dengan model; menguji (memvalidasi) model; memberi saran-saran. (5). Mengajukan dan memecahkan masalah, meliputi kemampuan mengajukan, merumuskan, mendefinisikan, dan menyelesaikan masalah dengan berbagai cara. (6). Representasi, yaitu kemampuan menerjemahkan, membedakan, dan menafsirkan bentuk-bentuk representasi matematika dan objek atau situasi, serta memhami hubungan diantara representasi yang berbeda. (7). Simbol, yaitu mampu menggunakan operasi simbolik, formal, dan bahasa teknik. (8). Alat dan teknologi, yaitu kemampuan menggunakan alat bantu, termasuk teknologi apabila diperlukan (Mizaniya, 2020).

Selain itu, kerangka pemikiran PISA untuk literasi matematika disusun menjadi tiga komponen luas: Situasi dan konteks di mana masalah berada dan digunakan sebagai sumber stimulus; Konteks matematika dengan berbagai masalah dan pertanyaan yang berhubungan, dan yang diatur oleh gagasan menyeluruh tertentu; Dan kompetensi matematis yang harus ada diaktifkan untuk menghubungkan dunia nyata (di mana masalah dihasilkan) dengan matematika, dan kemudian Digunakan untuk memecahkan masalah. Aspek penting dari literasi matematika adalah keterlibatan siswa dalam menggunakan matematika pada berbagai situasi. Siswa diperlihatkan materi tertulis atau permasalahan dalam berbagai situasi yang dapat dipikirkan siswa, kemudian mereka mendaftar pengetahuan matematika yang dimilikinya untuk menganalisis dan menghadapi masalah tersebut (Mizaniya, 2020).

Petingnya literasi numerasi ini, tidak kalah aktif dari upaya pemerintah dalam menggerakan literasi di sekolah dengan mewujudkan generasi emas pada abad ke-21. Literasi numerasi juga dapat 
meningkatkan peserta didik agar mampu mengatasi masalah dengan cara mengolah angka dengan benar. Literasi numerasi diajarkan kepada peserta didik bukan hanya dalam mata pelajaran matematika saja, tetapi diberikan melalui berbagai mata pelajaran lainnya untuk menggunakan matematika diberbagai situasi (Han Weilin, 2017:10).

Cara untuk menggerakan literasi numerasi dapat dilakukan melalui berbagai strategi. Menurut Kemendikbud (2017), strategi gerakan literasi di sekolah melalui beberapa tahapan pelaksanaan, yaitu ketersediaan sarana dan prasarana, kapasitas warga sekolah, dan kapasitas pemangku kepentingan. Strategi literasi numerasi dilakukan dengan menumbuhkan motivasi serta pemahaman peserta didik terhadap numerasi. Strategi ditunjang dengan fasilitas sarana dan prasarana untuk mendukung gerakan literasi numerasi di sekolah.

Literasi numerasi juga diterapkan melalui pembelajaran numerasi lintas kurikulum. Numerasi lintas kurikulum dilakukan dalam kurikulum 2013 saat ini yang menggunakan pembelajaran tematik. Hal ini senada dengan Ananto mengatakan bahwa literasi tidak sekedar membentuk pemahaman, tetapi juga cara berpikir. Dengan literasi, siswa diarahkan tidak hanya untuk memahami, tetapi juga untuk dapat menerapkan pemahamannya dalam kehidupan sehari-hari. Oleh karena itu, literasi perlu diintegrasikan ke dalam proses pembelajaran (Nahdi \& Yunitasari, 2019; Wahyuni, H.T, Setyosari, P \& Kuswandi, 2016). Salahsatunya pada literasi numerasi dalam pembelajaran tematik.

Penerapan literasi numerasi dalam pembelajaran tematik merupakan suatu pelaksanaan kegiatan pembelajaran yang dilakukan pendidik dengan menciptakan kegiatan pembelajaran yang melibatkan numerasi dalam beberapa mata pelajaran yang akan dipelajari. Simisal dalam satu tema terdapat beberapa mata pelajaran dengan di desain sendiri menggunakan metode, model, pendekatan, dan menyediakan media-media yang dapat memudahkan peserta didik untuk memahami materi numerasi dengan mudah (Yustitia \& Juniarso, 2020).

Selanjutnya, penelitian yang dilakukan oleh Ekowati et al., (2019) di SD Muhammadiyah 1 Kota Malang tentang program literasi numerasi dapat dilaksanakan secara tidak terjadwal. Sebagai contoh literasi numerasi dapat dilakukan pada waktu yang berbeda di setiap minggunya. Program literasi numerasi dapat dilaksanakan lebih dari 2 kali dalam setiap minggu dan dilakukan sebelum jam pembelajaran berlangsung. Pelaksanaan program literasi numerasi telah berjalan sesuai dengan tiga tahapan literasi sekolah menurut Faizah yakni: a) Tahap pembiasaan fokus pada penanaman konsep dasar matematika melalui kegiatan membaca. Bahan bacaan dalam penelitian ini yaitu literatur atau buku-buku matematika berkaitan literasi numerasi seperti ensiklopedia, buku penemu-penemu matematika dan sebagainya. b) Tahap pengembangan berorientasi pada pemahaman konsep dasar matematika melalui kegiatan menyelesaikan dan membahas soal materi literasi numerasi. Soal dapat disesuaikan dengan materi pembelajaran maupun soal yang tidak sesuai dengan materi pembelajaran. Hal ini bertujuan supaya siswa memahami materi yang telah dipelajari. c). Tahap pembelajaran fokus pada pengaplikasian konsep matematika dalam praktik pembelajaran dan tutor sebaya. Aktivitas atau praktik bermatematika dilakukan dengan dua cara yang meliputi praktik materi matematika dan kegiatan pembelajaran aktif di luar kelas. kegiatan praktik materi matematika dapat dilakukan dengan menyesuaikan materi mata pelajaran matematika dan tema pada pembelajaran tematik yang berkaitan dengan literasi numerasi. Kegiatan lain yang dilakukan pada tahap pembelajaran adalah tutor sebaya. Kegiatan tutor sebaya meliputi kegiatan diskusi kelompok atau focus group discussion, tanya jawab antar teman, permainan (games) dan presentasi (Heruman, 2013).

Literasi numerasi pada pembelejaran tematik pada siswa kelas atas di sekolah dasar dapat pula diterapkan melalui: (a). Jumlah pelatihan guru matematika dan nonmatematika; (b). Jumlah pembelajaran matematika berbasis permasalahan dan pembelajaran matematika berbasis proyek; (c). Jumlah pembelajaran nonmatematika yang melibatkan unsur literasi numerasi; (d). Nilai matematika peserta didik; dan (e) nilai matematika dalam PISA/TIMSS/INAP (Fiangga et al., 2019).

Pelaksanaan literasi numerasi dalam pembelajaran tematik siswa kelas atas sekolah dasar, tidak lepas dari upaya guru dalam mengkreasikan model, media, metode pembelajaran. Salahsatunya mengkreasikan siswa untuk membaca. Karena membaca berperan penting dalam kehidupan, karena salah satu cara untuk menambah pengetahuan didapat dari membaca. Adanya aktivitas membaca siswa dapat memperoleh beragam informasi yang dapat menunjang proses belajarnya. Peraturan Menteri Pendidikan dan Kebudayaan Nomor 23 Tahun 2015 tentang Penumbuhan Budi Pekerti, 
salah satunya mengenai kegiatan membaca buku non pelajaran selama lima belas menit sebelum waktu belajar dimulai. Kegiatan tersebut adalah upaya menumbuhkan kecintaan membaca kepada peserta didik dan pengalaman belajar yang menyenangkan sekaligus merangsang imajinasi. Kegiatan dalam Gerakan Literasi Sekolah dilaksanakan sesuai dengan kegiatan pembelajaran pada Kurikulum 2013. Implementasi Kurikulum 2013 di sekolah dasar menggunakan model pembelajaran terpadu. Salah satu model pembelajaran terpadu adalah pembelajaran tematik. Pembelajaran tematik dilaksanakan dengan menggabungkan beberapa mata pelajaran menjadi satu kesatuan dalam sebuah tema pembelajaran (Yunita Anindya et al., 2019).

\section{Simpulan}

Literasi numerasi dalam pembelajaran tematik siswa kelas atas sekolah dasar dapat dilakukan dengan pemberian stimulus pada siswa. Karakteristik siswa kelas atas perlu seorang guru smengarahkan pada pembelajaran yang tidak monoton. Stimulus yang dipilih hendaknya kontekstual, menarik, dan sebaiknya bersifat kekinian sehingga merangsang rasa ingin tahu siswa. Selain itu, juga adanya ketersediaan sarana dan prasarana, kapasitas warga sekolah, dan kapasitas pemangku kepentingan. Demikian pula dapat diupayakan melalui program literasi numerasi 2 kali dalam setiap minggu sebelum jam pembelajaran berlangsung, diadakan pelatihan guru matematika dan nonmatematika, diadakan pembelajaran matematika berbasis permasalahan dan pembelajaran matematika berbasis proyek, diadakan pembelajaran nonmatematika yang melibatkan unsur literasi numerasi, dan menumbuhkan kecintaan membaca kepada peserta didik dan pengalaman belajar yang menyenangkan sekaligus merangsang imajinasi.

\section{Referensi}

Ayuningtyas, N., \& Sukriyah, D. (2020). Analisis pengetahuan numerasi mahasiswa matematika calon guru. Matematika Dan Pendidikan Matematika, 9(02), 237-247. http://ejournal.unkhair.ac.id/index.php/deltapi/article/view/2299

Dayang, S., Izhar, S., \& Hidayah, R. Al. (2013). Analisis Penerapan Literasi Membaca Pada Pembelajaran Sosiologi di SMAN 1 Pulau Maya. Journal of Chemical Information and Modeling, 53(9), 1689-1699.

Dits Prasanti, D. R. F. (2018). Penelitian Kepustakaan (Library Research) dalam Penelitian Pendidikan IPA. Pembentukan Anak Usia Dini : Keluarga, Sekolah, Dan Komunitas, 2(1), 15. https://ejournal.uinib.ac.id/jurnal/index.php/naturalscience/article/view/1555/1159

Ekowati, D. W., Astuti, Y. P., Utami, I. W. P., Mukhlishina, I., \& Suwandayani, B. I. (2019). Literasi Numerasi di SD Muhammadiyah. ELSE (Elementary School Education Journal): Jurnal Pendidikan Dan Pembelajaran Sekolah Dasar, 3(1), 93. https://doi.org/10.30651/else.v3i1.2541

Fiangga, S., M. Amin, S., Khabibah, S., Ekawati, R., \& Rinda Prihartiwi, N. (2019). Penulisan Soal Literasi Numerasi bagi Guru SD di Kabupaten Ponorogo. Jurnal Anugerah, 1(1), 9-18. https://doi.org/10.31629/anugerah.v1i1.1631

Kawaryan, S. . (2018). Karakteristik siswa SD kelas rendah dan pembelajaranya.

Mahmud, M. R., \& Pratiwi, I. M. (2019). Literasi Numerasi Siswa Dalam Pemecahan Masalah Tidak Terstruktur. KALAMATIKA Jurnal Pendidikan Matematika, 4(1), 69-88. https://doi.org/10.22236/kalamatika.vol4no1.2019pp69-88

Mizaniya, M. (2020). Analisis Materi Pokok Matematika Mi/Sd. AULADUNA: Jurnal Pendidikan Dasar Islam, 7(1), 98. https://doi.org/10.24252/auladuna.v7i1 a10.2020

Nahdi, K., \& Yunitasari, D. (2019). Literasi Berbahasa Indonesia Usia Prasekolah: Ancangan Metode Dia Tampan dalam Membaca Permulaan. Jurnal Obsesi : Jurnal Pendidikan Anak Usia Dini, 4(1), 446. https://doi.org/10.31004/obsesi.v4i1.372 
Novitasari, D. (2016). Pengaruh penggunaan multimedia interaktif terhadap kemampuan pemahaman konsep matematis siswa. FIBONACCI: Jurnal Pendidikan Matematika Dan Matematika, 2(2), 8. https://doi.org/10.24853/fbc.2.2.8-18

Rafika, A. S., Yunan Putri, H., \& Widiarti, F. D. (2017). Sebagai Sumber Baru Untuk Kutipan. Cerita, 3(2), 13. https://core.ac.uk/download/pdf/285996222.pdf

Ramandanu, F. (2019). Gerakan Literasi Sekolah (Gls) Melalui Pemanfaatan Sudut Baca Kelas Sebagai Sarana Alternatif Penumbuhan Minat Baca Siswa. Mimbar Ilmu, 24(1), 10. https://doi.org/10.23887/mi.v24i1.17405

Septianti, N., \& Afiani, R. (2020). Pentingnya Memahami Karakteristik Siswa Sekolah Dasar di SDN Cikokol 2. As-Sabiqun, 2(1), 7-17. https://doi.org/10.36088/assabiqun.v2i1.611

Suswandari, M. (2018). Membangun budaya literasi bagi suplemen pendidikan di indonesia. Jurnal Dikdas Bantara, 1(1), 20-32.

Tyas, F., \& Pangesti, P. (2018). Menumbuhkembangkan Literasi Numerasi Pada Pembelajaran Matematika Dengan Soal Hots. Indonesian Digital Journal of Mathematics and Education, 5, 566-575.

Wahyuni, H.T, Setyosari, P \& Kuswandi, D. (2016). Implementasi pembelajaran tematik kelas 1 SD. Edcomtech, 1(2), 129-136.

Yanto, S \& Nelisa, M. (2014). Bibliografi beranotasi tugas akhir jurusan sistem produksi industri dan jurusan teknik kimia teknologi industri Padang tahun 2012-2013. Jurnal Ilmu Informasi Perpustakaan Dan Kearsipan, 3(1), 172-180.

Yunita Anindya, E. F., Suneki, S., \& Purnamasari, V. (2019). Analisis Gerakan Literasi Sekolah Pada Pembelajaran Tematik. Jurnal Ilmiah Sekolah Dasar, 3(2), 238. https://doi.org/10.23887/jisd.v3i2.18053

Yustitia, V., \& Juniarso, T. (2020). Literasi Matematika Mahasiswa Dengan Gaya Belajar Visual. Malih Peddas (Majalah Ilmiah Pendidikan Dasar), 9(2), 100-109. https://doi.org/10.26877/malihpeddas.v9i2.5044 